\title{
Consolidation of porous carbonate stones by an innovative phosphate treatment: mechanical strengthening and physical-microstructural compatibility in comparison with TEOS-based treatments
}

\author{
Gabriela Graziani, Enrico Sassoni ${ }^{*}$ and Elisa Franzoni
}

\begin{abstract}
For preservation of stones used in Cultural Heritage, affected by weathering processes that threaten their cohesion and mechanical properties, the application of consolidants is a common practice. However, available consolidating products generally exhibit some drawbacks that hinder their performance, in terms of either mechanical efficacy, compatibility with the substrate and/or durability. Ethyl silicate is currently the most widely used among stone consolidants; nevertheless, its reduced efficacy on calcitic substrates, together with its temporary hydrophobicity, its tendency to crack and its common formulation with volatile organic solvent, make the research for alternative consolidants for carbonate stones necessary. In this paper, a recently proposed new consolidation treatment based on the formation of hydroxyapatite inside the stone was tested on two different porous carbonate stones (Globigerina Limestone and Giallo Terra di Siena), and compared with TEOS-based treatments, frequently used for the consolidation of these lithotypes. The results show that the hydroxyapatite treatment exhibits a good efficacy in terms of mechanical properties and, compared to TEOS, it causes less pronounced alterations in open porosity and water transport properties. This makes the new treatment a potentially valid alternative to TEOS, especially in those situations where the possible presence of water behind the consolidated layer (e.g. in case of rising damp, condensation or infiltration) might threaten the durability of the consolidation intervention.
\end{abstract}

Keywords: Ethyl silicate, Hydroxyapatite, Stone consolidants, Limestone, Sandstone, Weathering

\section{Introduction}

Natural stones and mortars used in architecture and sculpture and exposed to outdoor conditions are affected by weathering phenomena hampering their cohesion and mechanical properties, thus making consolidation treatments necessary. Stone consolidation, however, needs careful designing and preliminary testing, as it is basically an irreversible intervention in most of the cases [1-4]. Moreover, consolidation might even result in an acceleration of materials decay [5,6], if unsuitable materials or treatment conditions are selected. For these reasons, the study of stone consolidants is of primary importance.

\footnotetext{
* Correspondence: enrico.sassoni2@unibo.it

Department of Civil, Chemical, Environmental and Materials Engineering (DICAM), University of Bologna, via Terracini 28, 40131 Bologna, Italy
}

Consolidation effectiveness is known to be influenced by a multitude of parameters $[7,8]$ and above all by the consolidant itself (in terms of active principle, solvent and concentration of the components), the substrate nature and weathering level, together with the application procedure and the environmental conditions, that might play a key role in on-site application.

The most used among stone consolidants is currently tetra-ethyl-ortho-silicate (TEOS) [1,3], whose effectiveness derives from hydrolysis-condensation reactions, that lead to the formation of amorphous silica inside stone pores [5,9-11]. The compatibility of the deposited silica gel with silicate substrates and its ability to form strong $\mathrm{Si}-\mathrm{O}-\mathrm{Si}$ bonds (that give the consolidant stability towards thermal weathering, solar light and oxidation, hence guaranteeing a 
high durability [5]) are the main advantages that make the use of this product so diffused. TEOS effectiveness, however, is known to be dependent on the presence of quartzitic fractions inside the substrate, allowing for chemical bonding. The reduced effectiveness of TEOS on carbonate substrates, compared to silicate ones, the temporary hydrophobicity of TEOS-treated stones and TEOS tendency to crack during drying are the main limitations of this consolidant when applied on carbonate stones [1]. TEOS efficacy is also linked to the solvent in which it is applied (that can be up to $25 \mathrm{wt} \%$ of the formulation), as solvent influences alkoxysilanes condensation reactions and hence their mechanical and physical properties. Solvent evaporation and gel syneresis (i.e. contraction due to condensation occurring between unreacted groups in the network [12]) during curing directly affect gel tendency to crack [13].

In order to overcome the limitations of TEOS in the treatment of carbonate stones, starting from 2010 [14] a new inorganic consolidant, based on the formation of hydroxyapatite (HAP) in the substrate, has been introduced and tested. HAP is formed inside the stone due to a reaction between an aqueous solution of diammonium hydrogen phosphate (DAP) and the calcite of the substrate. Experiments carried out so far on marble protection and porous stone consolidation have given very promising results, as HAP proved to be very effective on lithotypes with variable carbonate content [15-22]. HAP ability to develop high mechanical strength in just 48 hours curing, together with its application in aqueous solvent (non toxic), are further advantages of this treatment $[14,19]$.

In this study, the effectiveness of the HAP-treatment was tested and compared to that of TEOS on two carbonate stones, a limestone and a calcarenite with different mineralogical composition and microstructural features, namely Globigerina limestone (Malta) and Giallo Terra di Siena (Italy). Both lithotypes have been used in historical and modern buildings and, particularly in the case of Globigerina limestone, ethyl silicate is often used for consolidation of weathered elements (in spite of the reduced effectiveness of this consolidant on carbonate stones) mainly because of the lack of more suitable alternatives [3]. The HAP-treatment effects were evaluated in terms of mechanical effectiveness and compatibility with the substrate, and compared to those of TEOS, in order to determine whether HAP might be a valuable alternative to be employed for consolidation of these lithotypes.

\section{Experimental \\ Materials}

Two different lithotypes were used for the tests: Globigerina Limestone and Giallo Terra di Siena, from now on labelled as GL and GS, respectively, differing for porosity and mineralogical composition. In particular, GL is composed for about $90 \mathrm{wt} \%$ of calcite and exhibits small amounts of quartz and a total open porosity around $40 \%$ [23,24], while GS is mainly composed of calcite (around $80 \mathrm{wt} \%$ ), quartz and feldspars, and exhibits a total open porosity around 20\% [19].

Quarry slabs of both stones were cut into $5 \mathrm{~cm}$ cubes and core-drilled perpendicularly to bedding planes to obtain $2 \mathrm{~cm}$ diameter and $5 \mathrm{~cm}$ height cores. As samples naturally weathered in the field usually undergo alterations in porosity, liquid water transport properties and mechanical strength, all the samples used in this study were artificially weathered by heating prior to consolidants application. According to a previously developed methodology [14,23], samples were heated at $400^{\circ} \mathrm{C}$ for 1 hour (in the case of GS, after preliminary saturation with water and heating at $200^{\circ} \mathrm{C}$ for 1 hour), so as to induce new micro-crack formation at grain boundaries.

The HAP-based treatment was performed by using a $1 \mathrm{M}$ aqueous solution of DAP (Sigma-Aldrich).

Two different TEOS mixtures were used for the two lithotypes (a commercial mixture for GL, a mixture prepared in the laboratory for GS), maintaining the same catalyst (1 wt\% DBTL) and the same ratio between the active principle and the solvent, so that the only parameter to change was the solvent type. GL samples were treated with a commercial product composed of $75 \mathrm{wt} \%$ ethyl silicate and $25 \mathrm{wt} \%$ white spirit D40 (Estel 1000 by CTS s.r.l., Italy). GS samples were treated with a mixture of $75 \mathrm{wt} \%$ ethyl silicate and $25 \mathrm{wt} \%$ isopropyl alcohol.

\section{Methods}

All the samples were treated by brushing, as this is the most common application method usually adopted in the field [25]. Cylinders of both stones were treated on the whole external surface, while cubes were treated on one face perpendicular to the bedding planes. As usually recommended in the technical data sheets of commercial TEOS-based products, HAP and TEOS treatments were applied until apparent refusal (defined as the condition when stone surface remains wet for 1 minute after consolidant application [7]), which required about 10 brushing applications for GS and GL cylindrical samples, about 20 applications for GS cubes and 30 applications for GL cubes.

HAP-treated samples were left to cure for 48 hours wrapped in a plastic film to prevent evaporation, while TEOS-treated samples were left to cure for 4 weeks (as recommended by commercial TEOS products technical data sheets) in laboratory room conditions $\left(\mathrm{T}=20 \pm 2^{\circ} \mathrm{C}\right.$, $\mathrm{RH}=50 \pm 5 \%)$. 


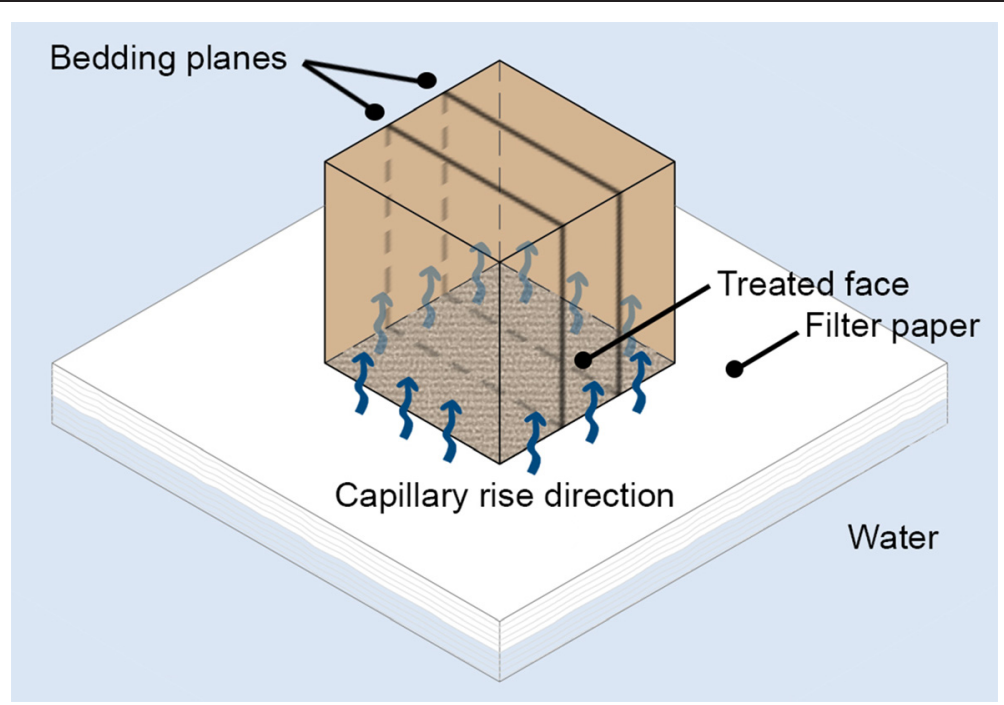

Figure 1 Sorptivity test: Schematic representation of sorptivity test on treated samples: water is let penetrate the samples through the treated face.

The performance of the two consolidants on the selected lithotypes was then evaluated in terms of mechanical strengthening and alteration in microstructure and transport properties. All tests were performed on treated and untreated samples, for comparison's sake.

Mechanical properties were determined on stone cores in terms of dynamic elastic modulus (by ultrasonic test, Matest instrument with $55 \mathrm{KHz}$ transducers) and tensile strength (by Brazilian splitting tension test), as these properties provide an estimation of the consolidant ability to restore stone cohesion and seal micro-cracks, together with providing an indication of its even distribution inside the sample. Tensile strength determination is particularly relevant when TEOS treated samples are under examination, as the formed silica gel can either create chemical bonds with the samples, hence exerting a proper binding action, or else just deposit inside stone pores, hence not giving significant benefit in terms of cohesion [1].

Stone porosity and pore size distribution were investigated by mercury intrusion porosimetry (MIP, Fisons Macropore Unit 120 and Porosimeter 2000 Carlo Erba) on fragments taken by chisel from the surface of stone cores, in order to investigate the alterations occurred in the consolidated layer of the sample. Microstructural alterations were expressed in terms of pore size distribution, total open porosity and average pore radius, defined as the radius corresponding to $50 \%$ of mercury intruded volume. Pore percentage below and above $0.1 \mu \mathrm{m}$ and $1 \mu \mathrm{m}$ were also determined, as an increase in the fractions of smaller pores is known to raise stone susceptibility to decay due to salt crystallization [26].

Stones transport properties were determined by sorptivity test, performed according to the EN 15801 [27],

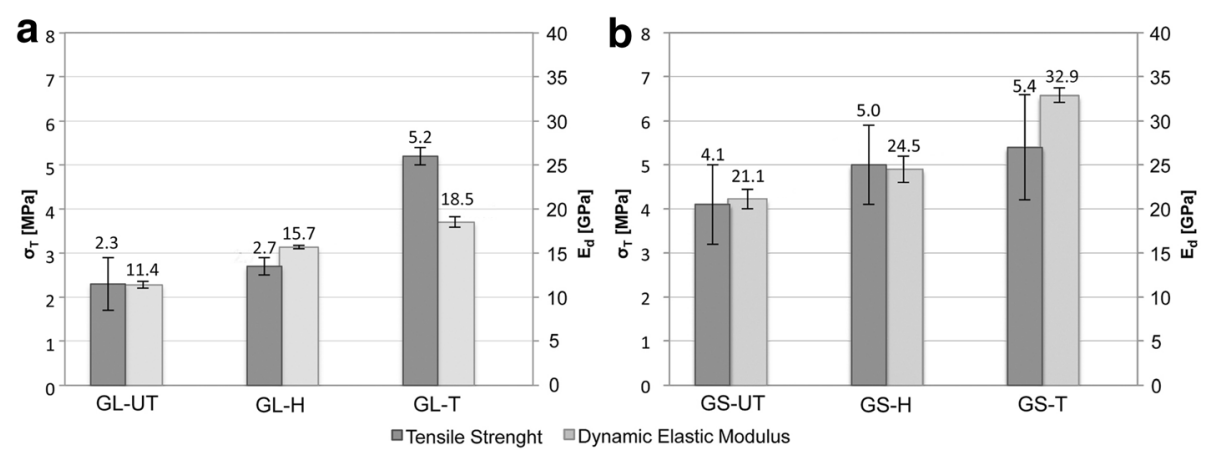

Figure 2 Mechanical properties: Tensile strength and dynamic elastic modulus untreated, HAP treated (-H) and TEOS treated (-T) samples of Globigerina Limestone a) and Giallo terra di Siena b). 

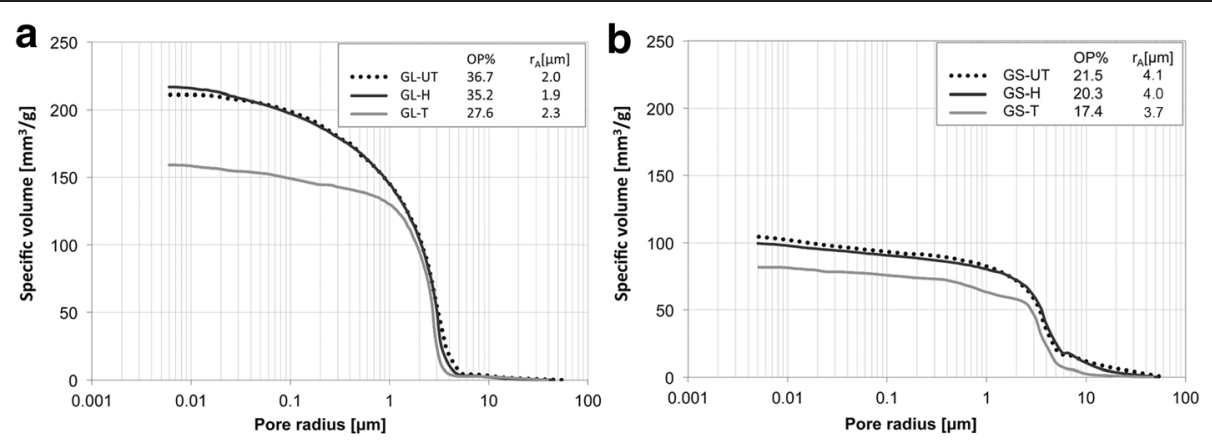

Figure 3 Samples pore size distribution before and after treatment: Pore size distribution, open porosity (OP) and average pore radius $r_{a}$ of untreated, HAP-treated and TEOS-treated samples of Globigerina Limestone a) and Giallo Terra di Siena b).

water being let penetrate the samples through the treated face, as in the scheme in Figure 1. The test was stopped after 24 hours, when saturation had already been reached for both stones, and the corresponding water absorption value was determined.

\section{Results and discussion}

Tensile strength and dynamic elastic modulus of treated and untreated GL and GS are reported in Figure 2. Both HAP and TEOS proved to have a high efficacy in enhancing GS mechanical properties, as tensile strength was increased, respectively, by $22 \%$ and $32 \%$ with respect to the untreated references, while dynamic elastic modulus was increased by $16 \%$ and $56 \%$, respectively. When the consolidants are applied to GL, the differences in the performances of HAP and TEOS are more marked, as increases of $17 \%$ and $126 \%$ in terms of tensile strength, and $38 \%$ and $63 \%$ in terms of dynamic elastic modulus were registered.

The consolidating effect of the HAP-treatment on both stones derives from HAP formation inside the material, determining a better bonding between the grains [19]. The high efficacy of TEOS is to be ascribed to the presence of quartzitic fractions in both tested stones, allowing for chemical bonding $[3,18,19]$. HAP was found to be slightly more efficient on GS than GL, in terms of tensile strength, in spite of the higher calcite content of

Table 1 Pore size distribution: Pore alterations on HAP treated and TEOS treated samples

\begin{tabular}{llll}
\hline Sample & $\mathbf{O P} \%<\mathbf{0 . 1} \boldsymbol{\mu m}$ & $\mathbf{0 . 1} \boldsymbol{\mu m}<\mathbf{O P} \%<\mathbf{1} \boldsymbol{\mu m}$ & $\mathbf{O P} \% \mathbf{1} \boldsymbol{\mu m}$ \\
\hline GL-UT & 2.1 & 9.3 & 25.2 \\
GL-H & 4.8 & 8.4 & 23.5 \\
GL-T & 2.5 & 3.3 & 22.5 \\
GS-UT & 2.3 & 2.2 & 17.0 \\
GS-H & 1.8 & 2.1 & 16.4 \\
GS-T & 1.3 & 2.7 & 13.5 \\
\hline
\end{tabular}

GL: this is probably to be ascribed to the different size and shape of micro-cracks that formed in the two stones after artificial weathering; indeed, HAP ability of sealing cracks substantially depends on the crack size and shape. This aspect is currently under further investigation.

The cited differences in the performances of TEOS on Globigerina Limestone and Giallo Terra di Siena, considering that higher improvements are obtained for GL which has a lower quartz content than GS, might be ascribed to the different formulations used: the commercial product based on white spirit was actually more effective than the alternative TEOS formulation based on isopropyl alcohol (having however the advantage of being less toxic). Hence, TEOS efficacy confirmed to be highly dependent on the solvent type [13]; when isopropyl alcohol is used, TEOS performances are comparable to those of HAP, while the formulation in white spirit leads to better mechanical performances.

Microstructural alterations induced by the two consolidants were examined in terms of pore size distribution, total open porosity and average pore radius, reported in Figure 3 and Table 1. As can be observed in Figure 3, HAP treatment resulted in a negligible alteration of samples porosity, while TEOS caused a certain pore occlusion, more relevant in the case of GL, correspondingly with the higher mechanical properties obtained for this lithotype. In terms of pore size distribution (Table 1), HAP resulted in a slight increase in the percentage of pores with radius $<1 \mu \mathrm{m}$ in the case of GL, while TEOS did not significantly increase the percentage of finer pores. Considering that stone consolidants are usually required to alter materials microstructure to the lowest possible extent $[3,26,28]$, and in particular to cause a minimum increase in "small" pores (having radius $<1 \mu \mathrm{m}$, according to [26]), both HAP and TEOS can be considered as fairly compatible in terms of alterations in porosity. Indeed, the decrease in open porosity induced by TEOS is rather limited, while the increase in small pores caused by HAP is not expected to cause any worsening of durability 

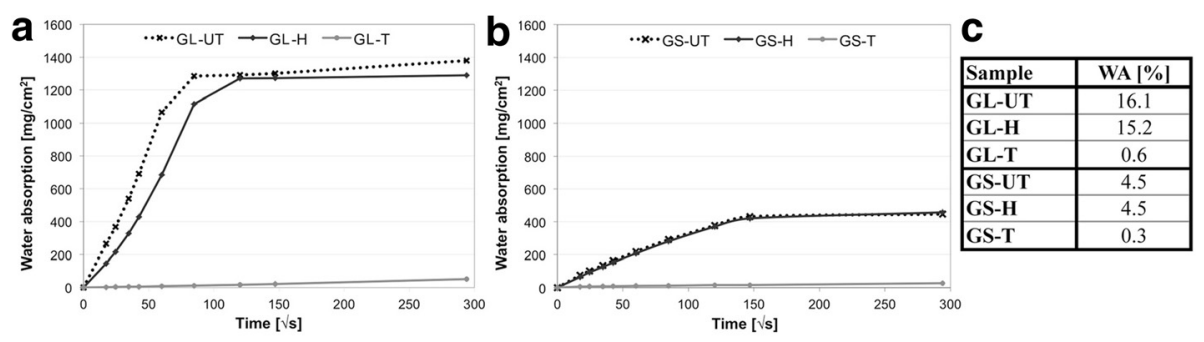

Figure 4 Sorptivity and total water absorption before and after treatment: Sorptivity curves of untreated, HAP treated and TEOS treated samples of Globigerina Limestone a) and Giallo Terra di Siena b) and c) total water absorption (WA) of GL and GS untreated and treated samples, after 24 hours of capillary water uptake.

to salt crystallization, considering that the total open porosity and the water sorptivity (see below) remain essentially unaltered after the HAP-treatment. Anyway, durability towards salt crystallization is a complex matter, hence specific studies on the behaviour of HAP- and TEOS-treated samples when subjected to salt crystallization cycles are currently in progress.

Water transport properties of the two stones before and after consolidation are reported in Figure 4. Correspondingly with the negligible reduction of stone porosity, water uptake of the samples after HAP-treatment is almost unaltered, especially in the case of GS, where water absorption after 24 hours is exactly the same as that of the untreated references. TEOS treatment, instead, dramatically alters water transport properties of the samples, even after 4 weeks of curing. Indeed, TEOS-treated samples exhibit negligible water uptake for 24 hours of contact with water. This can be ascribed to the reduction in samples porosity and, mostly, to the temporary hydrophobic effect of ethoxy groups, that remain in the stone until curing reactions are complete $[1,5]$. This may require several months $[16,17]$, during which it is impossible to apply any water-based treatment $[1,5]$. Moreover, in case water can enter the stone from behind the TEOS-consolidated stone layer (e.g., because of rising damp, not completely eliminated before the consolidation intervention, or because of condensation or infiltration), problems may arise during the period of temporary hydrophobicity, as water is blocked behind the consolidated layer and damage owing to salts and/or freezing-thawing may occur [1].

\section{Conclusions}

From the tests carried out on Globigerina Limestone and Giallo Terra di Siena, the following conclusions can be derived:

- both consolidants proved to be effective on the selected lithotypes, as they caused significant improvements in mechanical properties of both GL and GS. The HAP mechanical efficacy was found to be comparable to that of TEOS, when isopropyl alcohol was employed to reduce ethyl silicate toxicity (GS samples), while TEOS efficacy proved to be higher than that of HAP when white spirit was used as solvent (GL samples);

- TEOS efficacy proved to be much dependent on the product formulation: when isopropyl alcohol is used instead of white spirit, TEOS efficacy dramatically decreases;

- in terms of alterations in porosity, both consolidants can be considered as fairly compatible with GL and GS; in particular, HAP leads to basically no alteration in total open porosity and a very slight alteration in pore size distribution, whereas TEOS is responsible for more pronounced open porosity reductions;

- in terms of alterations in liquid water transport properties, HAP demonstrated a much higher compatibility than TEOS, as the former treatment caused no substantial alterations, while the latter treatment induced temporary hydrophobicity in the treated stones. This makes the application of waterbased treatments impossible for several months after treatment and may give rise to salt- and freezingrelated problems, in case water is present behind the consolidated, hydrophobic layer.

For these reasons, HAP seems to be a valuable alternative to TEOS for the selected lithotypes, as it allows to obtain a good efficacy in a much shorter curing time and a higher compatibility with the substrate. Additional parameters on which the treatment compatibility depends (e.g., alteration in water vapour permeability, colour change, etc.) have given promising results in previous studies on different lithotypes [14,19]. Further tests to assess the durability of HAP-treated samples are currently in progress.

\footnotetext{
Abbreviations

GL: Globigerina Limestone samples; GS: Giallo Terra di Siena samples; -UT: Untreated samples; -H: Hydroxyapatite-treated samples; -T: TEOStreated samples.
} 


\section{Competing interests}

The authors declare that they have no competing interests.

\section{Authors' contribution}

The whole work was conceived by GG, ES and EF and coordinated by EF. Experimental tests were carried out by GG and ES and supervised by EF. The interpretation of results was performed jointly. GG wrote the first draft of the manuscript, that was revised by ES and, finally, by EF. All authors read and approved the final manuscript.

\section{Acknowledgements}

Dr. Enzo Padula is gratefully acknowledged for collaboration on stone characterization.

Received: 30 May 2014 Accepted: 17 December 2014

Published online: 15 January 2015

\section{References}

1. Scherer GW, Wheeler GS. Silicate consolidants for stone. Key Eng Mater. 2009;391:1-25

2. Tulliani JM, Formia A, Sangermano M. Organic-inorganic material for the consolidation of plaster. J Cult Herit. 2011;12:364-71.

3. Maravelaki-Kalaitzaki P, Kallithrakas-Kontos N, Korakaki D, Agioutantis Z, Maurigiannakis S. Evaluation of silicon-based strengthening agents on porous limestones. Prog Org Coatings. 2006;57:140-8.

4. Maravelaki-Kalaitzaki P, Kallithrakas-Kontos N, Agioutantis Z, Maurigiannakis S, Korakaki D. A comparative study of porous limestones treated with silicon-based strengthening agents. Prog Org Coatings. 2008;62:49-60.

5. Wheeler G. Alkoxysilanes and the Consolidation of Stone (Research in conservation). Los Angeles: The Getty Conservation Institute; 2005.

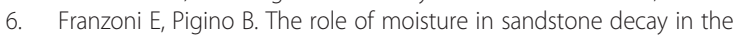
monumental cemetery of Bologna (Italy). In: Stefanaggi M, Verges-Belmin V, editors. Proceeding of Jardins de Pierres, conservation of stone in parks, gardens and cemeteries Conference. Paris, France: XL Print Saint-Etienne; 2011. p. 377.

7. Ferreira Pinto AP, Delgado RJ. Stone consolidation: the role of treatment procedures. J Cult Herit. 2008;9:38-53.

8. Moropoulou A, Haralampopoulos G, Tsiourva T, Auger F, Birginie JM. Artificial weathering and non-destructive tests for the performance evaluation of consolidation materials applied on porous stones. Mater Struct. 2003;36:210-7.

9. Franzoni E, Graziani G, Sassoni E, Bacilieri G, Griffa M, Lura P. Solvent-based ethyl silicate for stone consolidation: influence of the application technique on penetration depth, efficacy and pore occlusion. Mater Struct. doi:10.1617/s11527-014-0417-1.

10. Sandrolini F, Franzoni E, Pigino B. Ethyl silicate for surface treatment of concrete - Part I: Pozzolanic effect of ethyl silicate. Cem Concr Compos. 2012;34:306-12.

11. Xu F, Li D. Effect of the addition of hydroxyl-terminated polydimethylsiloxane to TEOS-based stone protective materials. J Sol-Gel Sci Technol. 2013;65:212-9.

12. Miliani C, Velo-Simpson ML, Scherer GW. Particle-modified consolidants: a study on the effect of particles on sol-gel properties and consolidation effectiveness. J Cult Herit. 2007;8:1-6.

13. Salazar-Hernandez C, Zarraga R, Alonso S, Sugita S, Cervantes J. Effect of solvent type on polycondensation of TEOS catalyzed by DBTL as used for stone consolidation. J Sol-Gel Sci Technol. 2009;49:301-10.

14. Sassoni E, Naidu S, Scherer GW. The use of hydroxyapatite as a new inorganic consolidant for damaged carbonate stones. J Cult Herit. 2011;12:346-55.

15. Matteini M, Rescic S, Fratini F, Botticelli G. Ammonium phosphates as consolidating agents for carbonatic stone materials used in architecture and cultural heritage: preliminary research. Int J Archit Herit: Conserv Anal Restoration. 2011;5:717-36.

16. Naidu S, Liu C, Scherer GW. Novel hydroxyapatite consolidant and the acceleration of hydrolysis of silicate-based consolidants, Proceedings of MRS Fall Meeting 2013. Boston (USA): 2013. (in press)

17. Naidu S, Liu C, Scherer GW. New techniques in limestone consolidation: Hydroxyapatite-based consolidant and the acceleration of hydrolysis of silicate-based consolidants. J Cult Herit. doi:10.1016/j.culher.2014.01.001.

18. Sassoni E, Franzoni E, Scherer GW, Naidu S. Consolidation of a porous limestone by means of a new treatment based on hydroxyapatite. New
York City (USA): Proceedings of 12th International Congress on

Deterioration and Conservation of Stone; 2012. in press.

19. Sassoni E, Franzoni E, Pigino B, Scherer GW, Naidu S. Consolidation of calcareous and siliceous sandstones by hydroxyapatite: comparison with a TEOS-based consolidant. J Cult Herit. 2013;14S:e103-8.

20. Naidu S, Sassoni E, Scherer GW. New treatment for corrosion-resistant coatings for marble and consolidation of limestone, in proceedings of "Jardins de Pierres - conservation of stone in parks, gardens and cemeteries". Paris (F). 2011;22-24:289-94.

21. Sassoni E, Naidu S, Scherer GW. Preliminary results of the use of hydroxyapatite as a consolidant for carbonate stones, MRS Online Proceedings Library, 1319, mrsf10-1319-ww04-05. doi:10.1557/opl.2011.735.

22. Franzoni E, Sassoni E, Graziani G. Brushing, poultice or immersion? Role of the application technique on the performance of a novel hydroxyapatitebased consolidating treatment for limestone. J Cult Herit. doi:10.1016/j. culher.2014.05.009.

23. Franzoni E, Sassoni E, Scherer GW, Naidu S. Artificial weathering of stone by heating. J Cult Herit. 2013;14S:e85-93.

24. Cassar J. Deterioration of the globigerina limestone of the Maltese islands, geological society, London. Spec Publ. 2002;205:33-49.

25. Ferreira Pinto AP, Delgado RJ. Consolidation of carbonate stones: influence of treating procedures on the strengthening action of consolidants. J Cult Herit. 2012;13:154-66.

26. Italian Recommendation NORMAL 20/85. Conservazione dei materiali lapidei: Manutenzione ordinaria e straordinaria. Rome: Istituto Centrale per il Restauro (ICR); 1985.

27. European Standard 15801. Conservation of cultural property - Test methods Determination of water absorption by capillarity. Brussels: European Committee for Standardization; 2010.

28. Rodrigues DJ, Grossi A. Indicators and ratings for the compatibility assessment of conservation actions. J Cult Herit. 2007;8:32-43.

Publish with ChemistryCentral and every
scientist can read your work free of charge
"Open access provides opportunities to our
colleagues in other parts of the globe, by allowing
anyone to view the content free of charge."
W. Jeffery Hurst, The Hershey Company.
- available free of charge to the entire scientific community
- peer reviewed and published immediately upon acceptance
- cited in PubMed and archived on PubMed Central
- yours - you keep the copyright
Submit your manuscript here:
http://www.chemistrycentral.com/manuscript/

